\title{
An Aptamer-based and Pyrene-labeled Fluorescent Biosensor for Homogeneous Detection of Potassium Ions
}

\author{
Cuiping Ma, ${ }^{\dagger}$ Heqing Huang, and Chunhui Zhao \\ Key Laboratory of Eco-chemical Engineering, Ministry of Education, College of Chemistry and Molecular \\ Engineering, Qingdao University of Science and Technology, Qingdao 266042, P. R. China
}

\begin{abstract}
A simple and homogeneous method based on aptamer and pyrene moieties for the detection of $\mathrm{K}^{+}$was developed. The aptamer was labeled by pyrene moiety at $3^{\prime}$ end as the molecular recognition element. In the presence of $\mathrm{K}^{+}$, the complementary oligonucleotide labeled by pyrene moiety at $5^{\prime}$ end was displaced from the aptamer, which was accompanied by a dramatic decrease of the excimer fluorescence of pyrene. However, the excimer fluorescence remains in the absence of the target. With optimum conditions, relative changes of the pyrene excimer fluorescence intensity were proportional to the concentrations of $\mathrm{K}^{+}$in the range of $6.3 \times 10^{-4}$ to $1.0 \times 10^{-2} \mathrm{M}$ with a detection limit of $5.0 \times 10^{-4} \mathrm{M}$. Importantly, in the presence of $\mathrm{Na}^{+}, \mathrm{NH}_{4}^{+}, \mathrm{Mg}^{2+}$ and $\mathrm{Ca}^{2+}$ cations of biological fluids, this method was able to detect $\mathrm{K}^{+}$ with high selectivity. In a word, the assay seems to have great potential applications, especially in biological fluids due to its simplicity, specificity and homogeneous detection.
\end{abstract}

(Received August 1, 2010; Accepted September 6, 2010; Published December 10, 2010)

\section{Introduction}

Potassium ions $\left(\mathrm{K}^{+}\right)$play a significant role as a transmitter in cells and in the regulation of membrane potential, nerve stimulation, and hormone secretion. ${ }^{1}$ Abnormal K ${ }^{+}$concentrations usually lead to several diseases. So specific recognition and quantitative detection of $\mathrm{K}^{+}$are extremely crucial in fundamental research as well as in clinical practice. However, most of the reported studies concerning $\mathrm{K}^{+}$avoided their clinical applications. For example, Minta et al. ${ }^{2}$ and Crossley et al. ${ }^{3}$ had reported $\mathrm{K}^{+}$detection in biological fluids that were based on fluorophores PBFI and coumarin diacid cryptand [2.2.2], respectively. However, poor selectivity against $\mathrm{Na}^{+}$was shown because they only tolerated 1.5- and 3.4-fold excesses of $\mathrm{Na}^{+}$in biological fluids, respectively. The development of practical polydiacetylene (PDA) liposome-based micro arrays to selectively detect potassium ions in the presence of $\mathrm{Na}^{+}$had been reported by Lee et al. ${ }^{4}$ The detection limit for the $30 \mathrm{~min}$ of incubation results in the microscope images was $0.5 \mathrm{mM}$. Other $\mathrm{K}^{+}$detection methods were also reported based on FRET (fluorescence resonance energy transfer) and aptamers modified by fluorophores. ${ }^{5-7}$ In 2005, Nagatoishi et al. reported thrombin-binding aptamer labeled by pyrene moieties at both ends for the detection of potassium in the presence of an excess of $\mathrm{Na}^{+}{ }^{8}$ However, these methods were greatly limited in their applicability because modified aptamers may cause reduction of affinity and specificity. ${ }^{9-12}$ Recently, Shi et al. reported an aptamer-based optical biosensor for $\mathrm{K}^{+}$detection, in which aptamer was unmodified as the molecular recognition element. ${ }^{13}$ It is very difficult and expensive to label oligonucleotides with pyrene at both ends and such methods are unsuitable for

$\dagger$ To whom correspondence should be addressed.

E-mail: sc169@163.com extensive applications. Therefore, we used two pyrene-labeled oligonucleotides for $\mathrm{K}^{+}$detection in this paper to circumvent the above described disadvantages. In addition, a visual method for $\mathrm{K}^{+}$detection was recently developed by Yang et al., ${ }^{14}$ which made $\mathrm{K}^{+}$detection simpler than before.

Pyrene is a well-characterized excimer-forming fluorophore which has been incorporated into synthetic oligonucleotides by several research groups. ${ }^{15-19}$ The fluorescence wavelength of pyrene monomer is about $395 \mathrm{~nm}$. The fluorescence wavelength is switched to about $485 \mathrm{~nm}$, when two pyrene molecules are brought into close proximity to form an excimer. ${ }^{20,21}$ The excimer fluorescence with characteristically large Stokes shift can be easily discriminated from the monomer fluorescence, thereby allowing homogeneous hybridization assays to be done even in the presence of excess unhybridized probes. ${ }^{22}$ Therefore, the experiment labeled by pyrene moiety overcomes common disadvantages, such as being tedious and time-consuming, which exist in the majority of hybridization experiments that use oligonucleotide probes artificially labeled with radioisotopes, fluorescent dye molecules, enzymes and biotin. ${ }^{23}$ Moreover, the pyrene excimer has a longer fluorescent lifetime ( $40 \mathrm{~ns})$ than that of the most of biological environment species $(<5 \mathrm{~ns}) .^{24,25}$ These two special features of pyrene excimer will make it have great potential application in biological environments.

In this report, we describe a simple and homogeneous assay method, which is based on aptamer and excimer-forming fluorophore pyrene. The aptamer and its complementary oligonucleotide were each labeled with one pyrene moiety, one in the $3^{\prime}$-position and the other in the $5^{\prime}$-position. Upon hybridization, the two fluorophore moieties came into close proximity and formed an excimer. In this paper, the thrombin-binding aptamer was chosen for $\mathrm{K}^{+}$detection. Aptamer forms a chair-type quadruplex structure upon binding to $\mathrm{K}^{+} \cdot{ }^{26-28}$ Therefore, in the presence of $\mathrm{K}^{+}$, the complementary oligonucleotide labeled by pyrene moiety at $5^{\prime}$ end was displaced 


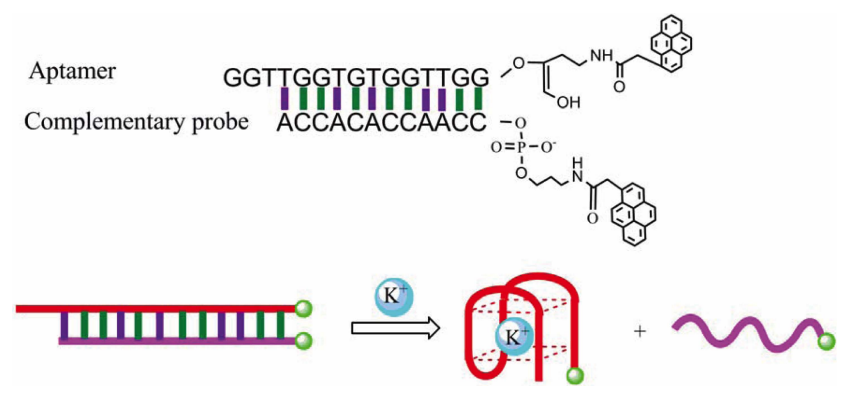

Fig. 1 General strategy for aptamer-based and pyrene-labeled fluorescent sensor and chemical structures of the pyrene labeled oligonucleotide.

from the aptamer. Simultaneously, a dramatic decrease of the excimer fluorescence could be observed.

\section{Experimental}

\section{Materials}

All oligonucleotides were synthesized by Shanghai Sangon Biological Engineering Technology \& Service Co., Ltd. and purified by HPLC. The thrombin-binding aptamer was the sequence d (GGT TGG TGT GGT TGG) for $\mathrm{K}^{+}$detection, which was modified by pyrene moiety at $3^{\prime}$ end. The complementary oligonucleotide was the sequence d (CCA ACC ACA CCA), which was modified by pyrene moiety at $5^{\prime}$ end. The sequence in boldface was complementary with the italic portion in the aptamer sequence. All chemicals were analytical grade and were used without further treatment. All solutions were prepared in deionized water.

\section{Apparatus and preferences}

All analyses were performed with a Hitachi F-4500 spectrophotometer (Tokyo, Japan) equipped with a xenon lamp. Fluorescence spectra were measured at an excitation wavelength of $340 \mathrm{~nm}$ and an emission wavelength at $485 \mathrm{~nm}$. The slit width was $10 \mathrm{~nm}$. The oligonucleotide quantitation was carried out on a Cary 50 UV-VIS-NIR spectrophotometer (Varian).

\section{General procedure}

The spectroscopic measurement experiments were carried out in $5 \mathrm{mM}$ Tris- $\mathrm{HCl}$ (pH 7.2) containing $20 \mathrm{mM} \mathrm{NaCl}$ and $2 \mathrm{mM}$ $\mathrm{MgCl}_{2}$. A $1 \mathrm{M} \mathrm{K}^{+}$stock solution was prepared by dissolving proper amounts of $\mathrm{KCl}$ in the buffer in a $1-\mathrm{mL}$ volume and diluting it 10 fold twice to $10 \mathrm{mM}$. All solutions were prepared by appropriate dilution from this standard. Similarly, the other stock solutions of cations were prepared by dissolving appropriate amounts of different $\mathrm{NaCl}, \mathrm{NH}_{4} \mathrm{Cl}, \mathrm{MgCl}_{2}$ and $\mathrm{CaCl}_{2}$ in the buffer described above. The fluorescence spectra of solutions were recorded at an excitation wavelength of $340 \mathrm{~nm}$ and an emission wavelength of $485 \mathrm{~nm}$.

\section{Experiment of quantitative analysis}

Aptamers and the complementary oligonucleotide were diluted from $1.0 \times 10^{-5} \mathrm{M}$ stock solution to $0.4 \mu \mathrm{M}$ in the buffer, and incubated at room temperature for $15 \mathrm{~min}$ to form an excimer. With the addition of $\mathrm{K}^{+}$, the reaction solution was incubated for $5 \mathrm{~min}$ at room temperature for binding of $\mathrm{K}^{+}$with aptamer, and the excimer fluorescence decrease was observed. The assay procedures for sodium, ammonium, calcium, and

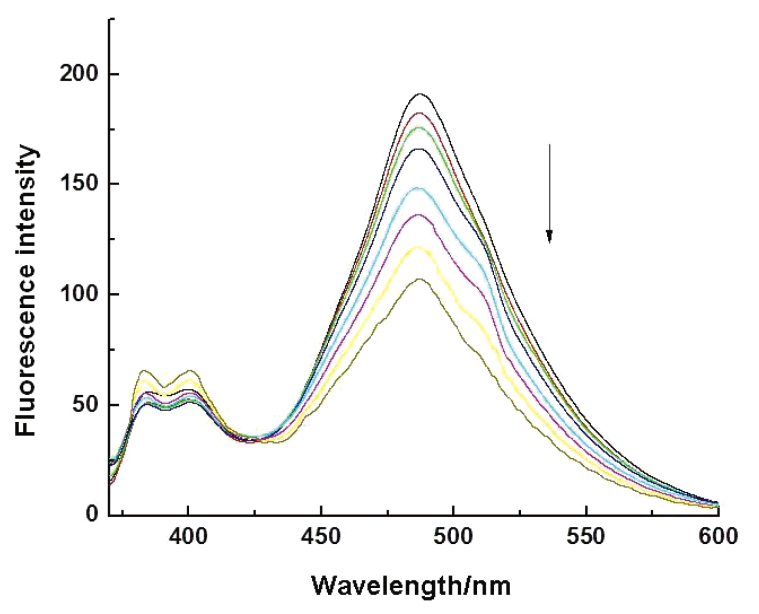

Fig. 2 Fluorescence changes of different concentrations of $\mathrm{K}^{+}$ions $(0,0.1,0.6,1,2,4,6,10 \mathrm{mM})$ with $0.4 \mu \mathrm{M}$ heteroduplex of aptamer and complementary oligonucleotide. Buffer: $5 \mathrm{mM}$ Tris- $\mathrm{HCl}, 20 \mathrm{mM}$ $\mathrm{NaCl}, 2 \mathrm{mM} \mathrm{MgCl}$, $\mathrm{pH}$ 7.2. $\lambda_{\mathrm{ex}}=340 \mathrm{~nm}$.

magnesium ions were the same as that for the $\mathrm{K}^{+}$, except for using $\mathrm{NaCl}, \mathrm{NH}_{4} \mathrm{Cl}, \mathrm{CaCl}_{2}$, and $\mathrm{MgCl}_{2}$ stock solutions. All the experiments were repeated three times.

\section{Results and Discussion}

Preparation of the complementary oligonucleotide probe

The relative stability of heteroduplex was predicted by the mfold program (available at the web site, http://mfold.bioinfo. rpi.edu/cgi-bin/dna-form1.cgi) to help select the appropriate complementary sequence to form an excimer. ${ }^{29,30}$ On the basis of thermodynamic prediction and $\mathrm{K}^{+}$reaction buffer, a 12-bp complementary oligonucleotide modified by pyrene moiety at $5^{\prime}$ end was designed. The complementary oligonucleotide was fully hybridized with the aptamer.

\section{The fluorescence measurements to detect target $K^{+}$ions}

The principle of aptamer-based and pyrene-labeled fluorescent biosensor for $\mathrm{K}^{+}$is shown in Fig. 1. In the presence of $\mathrm{K}^{+}$, the decrease of pyrene excimer fluorescence was observed for complementary oligonucleotides displaced from aptamers by targets. Therefore, an excimer-emission intensity decrease depending on the concentration of $\mathrm{K}^{+}$could be exhibited. To prove the sensitivity of the method, we tested the detection of different concentrations of $\mathrm{K}^{+}$by fluorometric titration with $\mathrm{KCl}$ (Fig. 2). Figure 2 showed the excimer fluorescence intensity decrease upon the addition of $\mathrm{K}^{+}$. In the absence of $\mathrm{K}^{+}$, the fluorescence spectrum exhibited no change of the excimer fluorescence intensity with two small monomer peaks at 380 and $395 \mathrm{~nm}$. It was reported that the fluorescence of the pyrene monomer coexisted when two pyrene moieties were labeled at the same end of the oligonucleotide. ${ }^{17}$ With the addition of $\mathrm{K}^{+}$, the resulting excimer-emission intensity decreased, owing to releasing the free complementary oligonucleotides, which brought a slight but steady increase in the emission peaks at 380 and $395 \mathrm{~nm}$.

\section{The sensitivity and specificity for detecting target $K^{+}$ions}

According to the protocols described above, the detection and quantification of $\mathrm{K}^{+}$ions had been achieved. The correlation curve of relative changes in excimer fluorescence intensity was 


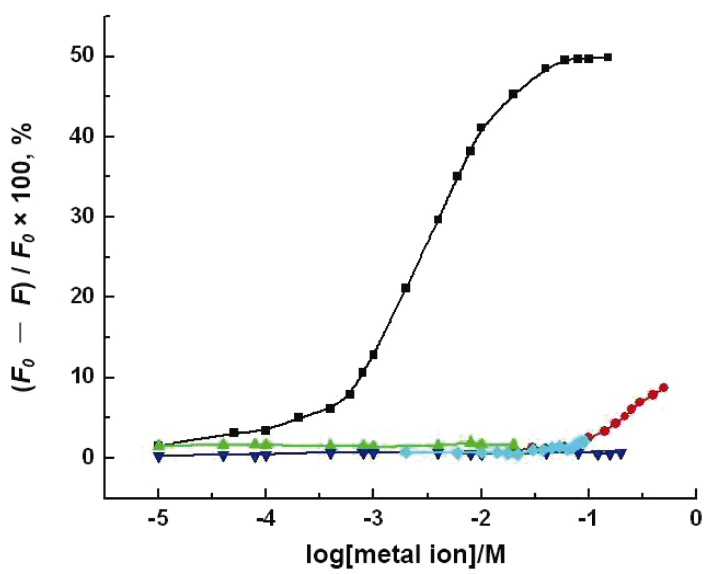

Fig. 3 Plots of the relative changes in fluorescence intensity (\%) of heteroduplex of aptamer and complementary oligonucleotide with different concentrations of $\mathrm{KCl}(\boldsymbol{\bullet}), \mathrm{NaCl}(\bullet), \mathrm{MgCl}_{2}(\bullet), \mathrm{CaCl}_{2}(\boldsymbol{\bullet})$, and $\mathrm{NH}_{4} \mathrm{Cl}(\boldsymbol{\nabla}) . \lambda_{\mathrm{ex}}=340 \mathrm{~nm}$. [Heteroduplex] $=4.0 \times 10^{-7} \mathrm{M}$.

constructed against the concentrations of $\mathrm{K}^{+}$ions (Fig. S1 (Supporting Information)). Therefore, quantitative analysis of an unknown $\mathrm{K}^{+}$ions concentration was also achievable. With the addition of $\mathrm{K}^{+}$ions, the decrease in excimer emission was observed in the concentration range of $0-100 \mathrm{mM}$. At the

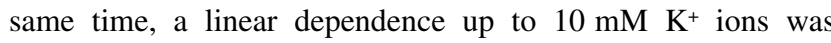
achieved. The detection limit for the $5 \mathrm{~min}$ of incubation was $0.5 \mathrm{mM}$, which allowed good results because the concentration of $\mathrm{K}^{+}$ion in serum is in the range of $3.5-5.3 \mathrm{mM}$. The methodology showed excellent sensitivity for the detection of $\mathrm{K}^{+}$ions.

To assess the specificity of the method, we also monitored changes in excimer fluorescence of oligonucleotide probes in the presence of $\mathrm{Na}^{+}, \mathrm{Mg}^{2+}, \mathrm{Ca}^{2+}$, and $\mathrm{NH}_{4}{ }^{+}$ions. The relative changes of excimer fluorescence intensities were plotted against the amount of $\mathrm{K}^{+}$ions (Fig. 3). With the addition of different cations, only the excimer emission of $\mathrm{K}^{+}$decreased dramatically. For $\mathrm{Na}^{+}, \mathrm{Ca}^{2+}, \mathrm{Mg}^{2+}$ and $\mathrm{NH}_{4}{ }^{+}$ions, the changes of relative excimer-emission intensities were very weak due to their weak binding affinity with thrombin-binding aptamer. ${ }^{8,31}$ Hence, the proposed method represents good specificity for $\mathrm{K}^{+}$ions over $\mathrm{Na}^{+}, \mathrm{Mg}^{2+}, \mathrm{Ca}^{2+}$, and $\mathrm{NH}_{4}{ }^{+}$ions at experimental condition.

$\mathrm{K}^{+}$ions coexist with an excess of $\mathrm{Na}^{+}$ions in extracellular conditions. At present, the specificity for $\mathrm{K}^{+}$against $\mathrm{Na}^{+}$ions was rather low for many studies concerning $\mathrm{K}^{+}$ions sensors, so such the monitoring of $\mathrm{K}^{+}$in extracellular condition was very difficult. ${ }^{32,33}$ Thereby the study of the interference of $\mathrm{Na}^{+}$ becomes very essential. In this paper, the dependence of the excimer emission was examined in the presence of $\mathrm{Na}^{+}$and $\mathrm{K}^{+}$ ions for the interference of $\mathrm{Na}^{+}$(Fig. S2 (Supporting Information)). Fortunately, $2 \mathrm{mM} \mathrm{KCl}$ could still be well detected in the presence of $100 \mathrm{mM} \mathrm{NaCl}$. The interference result from $\mathrm{Na}^{+}$further indicated our method seemed to be very good selectivity for $\mathrm{K}^{+}$ions against $\mathrm{Na}^{+}$ions.

\section{Conclusions}

A simple and homogeneous assay had been developed for the detection of $\mathrm{K}^{+}$ions, and the method can be exploited for the monitoring any targets such as proteins, DNA and RNA by the forming and change of the fluorescence of pyrene excimer emission. The excimer fluorescence could be easily discriminated from the monomer fluorescence, thereby allowing homogeneous hybridization assays to be done even in the presence of excess unhybridized probes. Therefore, the methodology presented here represents an excellent sensitivity for $\mathrm{K}^{+}$detection. The method demonstrated a linear relationship with the concentration of $\mathrm{K}^{+}$ions ranging from $6.3 \times 10^{-4}$ to $1.0 \times 10^{-2} \mathrm{M}$, and a detection limit of $5.0 \times 10^{-4} \mathrm{M}$ was achieved. Especially, the interference from $\mathrm{Na}^{+}$ions was very minor. The good selectivity for $\mathrm{K}^{+}$against other species such as $\mathrm{Na}^{+}$allows our method great potential applications in biological environment.

In addition, the simultaneous emission of the excimer and monomer forms of pyrene, and the presence of an isobestic point in the fluorescence spectrum shown on Fig. 2 present the interesting possibility of using this sensor as a ratiometric probe. More importantly, the pyrene excimer has a much longer fluorescence lifetime $(40 \mathrm{~ns})$ than that of the biological background ( $5 \mathrm{~ns})$, and time-resolved measurements can be used to eliminate the biological background. ${ }^{23,34}$ Therefore, it is very possible to detect $\mathrm{K}^{+}$ions in serum and living cells by time-resolved fluorescence measurements by our method with its simplicity, sensitivity, specificity and homogeneous detection.

\section{Acknowledgements}

The work was supported by the National High-tech R\&D Program (863 Program, No. 2007AA09Z113), National Natural Science Foundation of China (No. 20977055), Shandong Provincial Natural Science Foundation of China (No. Y2007E03), State Key Laboratory Foundation of Geological Processes and Mineral Resources (No. GPMR200924) and Key Lab Foundation of Biogeology and Environmental Geology of Ministry of Education (No. BGEGF200804).

\section{Supporting Information}

Additional information as noted in text. This material is available free of charge on the web at http://www.jsac.or.jp/ analsci/.

\section{References}

1. B. Alberts, A. Johnson, J. Lewis, M. Raff, K. Roberts, and P. Walter, "Molecular Biology of the Cell", 4th ed., 2002, Garland, New York.

2. A. Minta and R. Y. Tsien, J. Biol. Chem., 1989, 264, 19449.

3. R. Crossley, Z. Goolamali, and P. G. Sammes, J. Chem. Soc. Perkin Trans., 1994, 2, 1615.

4. J. Lee, H. J. Kim, and J. Kim, J. Am. Chem. Soc., 2008, $130,5010$.

5. S. Nagatoishi, T. Nojima, E. Galezowska, A. Gluszynska, B. Juskowiak, and S. Takenaka, Anal. Chim. Acta, 2007, $581,125$.

6. H. Ueyama, M. Takagi, and S. Takenaka, J. Am. Chem. Soc., 2002, 124, 14286.

7. S. Takenaka, H. Ueyama, T. Nojima, and M. Takagi, Anal. Bioanal. Chem., 2003, 375, 1006.

8. S. Nagatoishi, T. Nojima, B. Juskowiak, and S. Takenaka, Angew. Chem., Int. Ed., 2005, 117, 5195.

9. S. Beyer, W. U. Dittmer, and F. C. Simmel, J. Biomed. Nanotechnol., 2005, 1, 96. 
10. S. Jhaveri, M. Rajendran, and A. D. Ellington, Nat. Biotechnol., 2000, 18, 1293.

11. R. Nutiu and Y. Li, Angew. Chem., Int. Ed., 2005, 44, 1061.

12. N. Li and C. M. Ho, J. Am. Chem. Soc., 2008, 130, 2380.

13. C. Shi, H. X. Gu, and C. P. Ma, Anal. Biochem., 2010, 400, 99.

14. X. Yang, T. Li, B. L. Li, and E. Wang, Analyst, 2010, 135, 71.

15. K. Yamana, M. Takei, and H. Nakano, Tetrahedron Lett., 1997, 38, 6051.

16. R. H. Yang, Y. Zhang, K. A. Li, F. Liu, and W. H. Chan, Anal. Chim. Acta, 2004, 1, 97.

17. F. D. Lewis, Y. Zhang, and R. L. Letsinger, J. Am. Chem. Soc., 1997, 119, 5451.

18. P. Conlon, C. Y. Yang, Y. R. Wu, Y. Chen, K. Martinez, Y. Kim, N. Stevens, A. A. Marti, S. Jockusch, N. J. Turro, and W. H. Tan, J. Am. Chem. Soc., 2008, 130, 336.

19. T. J. Matray and E. T. Kool, J. Am. Chem. Soc., 1998, 120, 6191.

20. H. Zhu and F. D. Lewi, Bioconjugate Chem., 2007, 18, 1213.

21. M. Masuko, H. Ohtani, K. Ebata, and A. Shimadzu, Nucleic Acids Res., 1998, 26, 5409.

22. P. L. Paris, J. M. Langenhan, and E. T. Kool, Nucleic Acids Res., 1998, 16, 3789.
23. L. J. Kricka, "Nonisotopic DNA Probe Techniques", 1992 Academic Press, San Diego, CA

24. C. J. Yang, S. Jockusch, M. Vicens, N. J. Turro, and W. Tan, Proc. Natl. Acad. Sci. U. S. A., 2005, 102, 17278.

25. A. A. Marti, X. Li, S. Jockusch, Z. Li, B. Raveendra, S Kalachikov, J. J. Russo, I. Morozova, S. V. Puthanveettil, J. Ju, and N. J. Turro, Nucleic Acids Res., 2006, 34, 3161.

26. L. C. Bock, L. C. Griffin, J. A. Latham, E. H. Vermaas, and J. J. Toole, Nature, 1992, 355, 564.

27. E. Baldrich and C. K. O'Sullivan, Anal. Biochem., 2005, 341, 194.

28. W. Wang, C. Chen, M. Qian, and X. S. Zhao, Anal. Biochem., 2008, 373, 213.

29. J. J. Santa Lucia, Proc. Natl. Acad. Sci. U. S. A., 1998, 95 , 1460.

30. M. Zuker, Nucleic Acids Res., 2003, 31, 3406.

31. F. He, Y. Tang, S. Wang, Y. Li, and D. Zhu, J. Am. Chem. Soc., 2005, 127, 12343.

32. A. Yamauchi, T. Hayashita, S. Nishizawa, M. Watanabe, and N. Teramae, J. Am. Chem. Soc., 1999, 121, 2319.

33. C. Li, G. L. Law, and W. T. Wong, Org. Lett., 2004, 6, 4841.

34. J. B. Birks, "Wiley Monographs in Chemical Physics", 1970, Wiley, New York 